\title{
SYSTEMIC MODELING AND RELATIONS THINKING FOR RISK ASSESSMENT AND IT RESOURCES ALIGNMENT
}

\author{
Author(s) / Auteur(s) : \\ Panagiotis PAPAIOANNOU \\ University of Piraeus, Hellenic Society for Systemic Studies (HSSS) \\ p.papaioannou@gmail.com \\ Prof. Nikitas ASSIMAKOPOULOS \\ University of Piraeus, Hellenic Society for Systemic Studies (HSSS) \\ assinik@unipi.gr
}

\begin{abstract}
Résumé :
Systems of any kind expose behaviors that are not directly related to the individual attributes or behaviors of their constituting elements. These are known as emergent behaviors and their existence is a challenge for the manager who oversees an organization or when an intervention is attempted. In this study we argue that interactions or relations provide the main contribution to the existence of the emergent properties and studying these relations can be the starting point for examining or assessing emergent properties or behaviors. Two typical examples of emergent behaviors in an organization which operates as a sociotechnical system are: (a) risk and opportunities and $(b)$ the effectiveness of the information systems. The most systemic organizational paradigms are management systems following an ISO management standard, like ISO 9001:2015. Thus, our approach is aimed at systems of this type.
\end{abstract}

Keywords / Mots-clés :

Systemic Approach, Modeling, Relations, Risk, ,Business-IT Alignment, ISO Management Systems

\section{INTRODUCTION}

The systemic approach is stated explicitly or implicitly, throughout any ISO management system standard. A systemic principle is that the behavior of a system emerges as a result of the interactions or relations between its elements (Senge, 2006). This way the capabilities, weaknesses and, accordingly, the opportunities and the risks arise from the existence and quality of the relations between system elements. Thus, examining relations can be the base for identifying risks and for conducting the risk assessment.

The same approach can be used to address the timeless issue of Business - IT alignment. Relations carry information and, in most cases within the organization, the interaction takes place through information systems. A means of assessing how well information systems are aligned to the business processes is to look at the information exchanged; proper data in the appropriate variety as described in Stafford Beer's Viable System Model (Beer, 1979).

There are a lot of elements inside and around the organization that constitute a broader functioning system. These include processes, resources, employees, customers, other stakeholders, regulations, even organizational values henceforth called the "extended system". The proposed methodology starts by creating a conceptual model (a system) using the Design and Control Systemic Methodology (DCSYM) (Assimakopoulos \& Theocharopoulos, 2009). The model includes the processes of the organization, the elements of the context, the resources and the relations among them. The existence or appropriateness of a relation can be the source of an opportunity or risk. The information transformation, which takes place through the relation, is a means to assess the IT Resources Alignment with the organizational system. 


\section{SYSTEMIC BACKGROUND}

\section{Complexity in modern organizations}

Complexity is one of the main issues in modern organizations and has been the subject of studies both in business community and academia (Ganco, 2014; Schneider, Wickert \& Marti, 2016). It is found not only in large systems such as cities or big organizations, as it was in the past, but in every aspect of our lives, like the products we design and buy, our jobs and the organizational structures we oversee (Sargut \& McGrath, 2011).

Although complexity itself is not easy to define and there is not a unique definition of complexity in the scientific community, Complexity Science can be described as "the study of the phenomena which emerge from a collection of interacting objects" (Johnson, 2009).

The definition of complexity depends on the perspective. There can be Behavioural Definitions, Structural Definitions and Constructive Definitions and they may depend on the critical framework of the system, the observer and the context. Complexity can be defined as "the degree of difficulty in accurately predicting the behaviour of a system over time" (Wade \& Heydari, 2014). This definition correlates complexity with uncertainty and places risk identification on a new basis as a problem of complex systems.

Complexity is more than ever present in modern organizations as well as in their environment and is enlarged due to the interdependence of the elements within the systems. It is related to their efforts to survive and to be as competitive as possible and raises needs for organizational adaptation (Fabac, 2010).

\section{Systems Thinking and emergent system behaviours}

Systems Thinking employs concepts and principles from System Science to understand real world situations, to manage interdependencies, to provide the means for effective design and interventions and, finally, to simplify complexity (Gharajedaghi, 2011).

Systems Thinking is a discipline for seeing wholes as it is also a framework for focusing on interrelationships rather than isolated elements. Moreover, it is also a set of general principles and a set of tools spanning a range of heterogeneous scientific fields that have been applied to understand a wide range of complex systems (Senge, 2006).

A system can be defined as "a set of elements in interaction" (Bertalanffy, 1968) or "a set of entities with relations between them" (Langefors, 1995). A more precise and systemic definition which includes the boundary and the interaction with the environment is that a system is "a network of interacting agents producing a space with a well-defined boundary that is open in the sense of thermodynamics" (Zimmermann, 2017).

Systems approach can be considered as a means to deal with complex problematic situations or as a management practice. According to that, given a certain objective in a very complex network of interactions, the System Specialist(s) tries to find ways and means for its realization considering alternative solutions and choosing those promising optimization at maximum efficiency and minimum cost (Bertalanffy, 1968). Until now, understanding an organization is a trivialized issue and lacks a holistic approach. Shifting towards the Systems Approach helps to change this situation (Ryan, 2007)

Emergence is a concept closely related to systems. It refers to attributes or behaviours observed at the system's level in contrary to individual behaviours. According to Checkland (1999), emergence occurs when "entities exhibit properties which are meaningful only when attributed to the whole, not to its parts". Emergence is the behaviour of the system due to interactions and relations between its elements rather than isolated activities. Emergent behaviour occurs as a combined whole of the system structure, the allowable interactions and the behaviour and properties of individual elements. A property of a complex system is defined as an emergent one in the case that "although it arises out of the properties and relations characterizing its simpler constituents, it is neither predictable from, nor reducible to, these lower-level characteristics" (Honderich, 1995). 
Emergence may vary in the intensity at which it occurs. Based on the type and number of feedback loops that exist in the organizational model, emergence can be classified as Simple (Intentional or Unintentional), Weak (Stable or Instable), Multiple and Strong (Fromm, 2005).

\section{Risk as an emergent system behaviour due to complexity, relationships and interactions}

Risk is the effect of uncertainty where effect is defined as a deviation from the expected and may be positive or negative (ISO, 2016). The purpose of Risk Management is to prevent, reduce or alter the consequences identified by the risk assessment (Aven \& Renn, 2010).

From the Systems Engineering perspective, Hitchins (2007) focuses on interaction rather than structure stating that "emergent properties, capabilities and behaviours derive from interactions between the parts, and are traceable therefore principally to coupled processes, rather than to structure". He argues that the purpose, diffused throughout the whole system is the root of the emergence (p. 295). Hitchins also points out that emergent behaviour is not always beneficial (p. 15) and one of the roles of systems engineering is to create the "requisite emergent properties" in order to support the system purpose and to avoid system failures. On the other hand, Sillitto (2010) proposes that synergistic interactions cause emergence that can be exploited for maximizing opportunities.

According to Aven and Renn (2010), the complexity and the driving forces in the modern world introduce "new challenges to risk governance" which result "the emergence of systemic risks" whose investigation is based on interdependencies and risk propagation between risk clusters. They also mention that "high complexity and uncertainty favour the emergence of ambiguity" and that the high level of complexity is one of the main challenges during the risk assessment phase.

Johansen and Rausand (2014) relate complexity with uncertainty in three ways: (a) complexity can be one of the sources of uncertainty; (b) it is another type of uncertainty since it causes deviations from what is designed, planned or assumed, (c) introduces limitations when analysing uncertainty. Peterson (2015) notes that risk and opportunity increase as a system becomes more and more complex.

From the above, it is deduced that the behaviour of a system emerges as a result of the relations and the interactions between its components. The emergent properties, capabilities and behaviours are not always desirable; hence they may impose uncertainty and risk. Nevertheless, they may cause opportunities as well. Uncertainty and risk seem to be emerging properties of systems. Therefore, systemic approach can help to create the requisite emergence regarding the purpose of the system and, in case of uncertainty and risk, to regulate the effect of uncertainty eliminating negative consequences of risk events and maximizing possible opportunities.

\section{Context, Processes and Risk in ISO Management Systems}

International Organization for Standardization (ISO) has developed a series of standards for organizational management known as ISO Management Systems Standards (MSS). A management system is the way in which an organization manages the inter-related parts of its business in order to achieve its objectives (ISO, 2017). ISO, in Quality Management Principles, states that "Consistent and predictable results are achieved more effectively and efficiently when activities are understood and managed as interrelated processes that function as a coherent system" (ISO, 2015a).

ISO/IEC Annex SL (ISO, 2016), produced by ISO Technical Management Board in order to provide a common approach to developing new or to revising existing Management Systems Standards (MSS). The objective was consistent and compatible multiple MSS easier to implement and co-exist in an organization. ISO Annex SL in many points describes the organization as a system combining the process approach and risk-based thinking. As stated in Annex SL 2016, process is defined as a "set of interrelated or interacting activities which transform inputs into outputs" and processes are among the means for the organization to achieve its objectives while the management system includes the necessary processes and their interactions. In Annex SL, risk is defined as the "effect of uncertainty" and the organization shall manage risks and opportunities integrating the required actions into the management system processes. 
Annex SL has already been used in several standards and it will be adopted in future revisions of all standards. The most recent revision of ISO 9001 (ISO 9001:2015) is one of them (ISO, 2015b). ISO 9001:2015, being systemic by its nature, pays great attention to processes and their interactions and suggests that they should be managed as a whole with an overall focus on risk-based thinking. In this standard, risk identification is associated with the context of the organization, the resources and the processes themselves.

Each organization can implement Risk Assessment and Management in its own way, nevertheless ISO/IEC 31010, Annex B (ISO, 2009) provides 31 risk assessment techniques. Regarding risk issues in ISO 9001:2015, ISO states that risk lies in every aspect of the management system (ISO, 2015c). More specifically it is stated that, when providing resources, "risk is implicit whenever 'suitable' or 'appropriate' is mentioned". Therefore, considering the resources needed by a process as inputs of this process, their existence or appropriateness can be the source of an uncertainty which implies a risk or opportunity.

From the foregoing it is shown that the systemic approach is explicit or implicit in any ISO MSS following the Annex SL directives such as ISO 9001:2015. In order to perform risk assessment in such systems, we propose a relations-based approach based on a model of the whole system. The proposed methodology is to create a conceptual model of the system consisting of the processes of the organization, the elements of the context, the resources and the relations between them. According to this approach, any legal requirements, stakeholders' perspectives, and even resources availability, can be considered as inputs to a process. Their existence or appropriateness or the uncertainty about it, can be the source of an opportunity or risk.

\section{Modeling as a means to reduce complexity}

Loper and Register (2015) define a model as a physical, mathematical, or otherwise logical representation of a system, entity, phenomenon, or process whose purpose is to simplify the real-world which is too complex to be fully understood by humans. They consider modeling as a "purposeful abstraction of the reality" which reduces the real-world complexity by including those real-world elements "that form a reasonable or adequate approximation required for the purpose at hand".

Modeling, as a means to deal with complexity, has many applications in a large variety of areas including management (Flood \& Carson, 2013). Model-based approaches will enable understanding of complex system behavior much earlier in the product life cycle (INCOSE, 2014). Models are used intentionally or unintentionally to manage or to govern systems. From the cybernetic point of view, "every good regulator of a system must be a model of that system" (Conant \& Ashby, 1970). Managers use models to deal with the systems they oversee or problems they face but "the quality of their work will necessarily be limited by the quality of their models" (Ríos, 2010).

\section{The Design and Control Systemic Methodology (DCSYM) as a modelling tool}

DCSYM, as described by Assimakopoulos and Theocharopoulos (2009), apart from its systemic characteristics, provides a simple yet consistent notation for describing systems. It is based on simple rules, a consistent mathematical background and employs diagrams aiming at effectively guiding a multi-agent dialectic process about boundary critiques, system structure, organizational procedures and interventions. It can be used as a conceptual modelling tool and its simplicity and generality make it suitable for use in a variety of application fields.

The very basic elements of DCSYM are the Individual, the System and Subsystem and the Relations between them (Figure 1). 


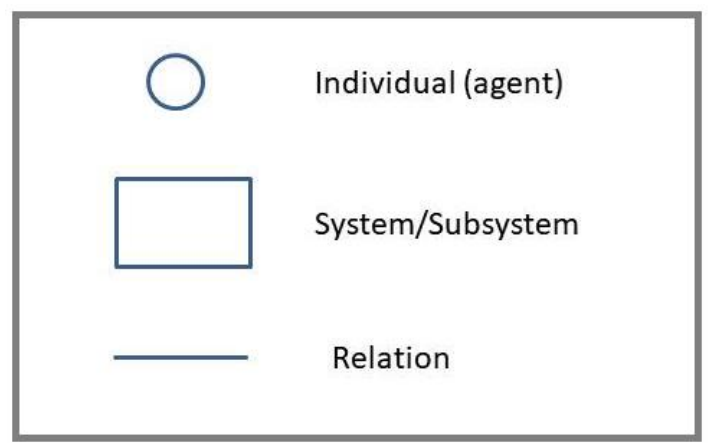

Figure 1. DCSYM elements

The Individual, depicted as a circle, represents an agent which is the smallest possible purposeful entity. A rectangle represents a system. A system may include other systems as subsystems and individuals as well. DCSYM also provides a notation to label the nesting level of each of these elements. Relations between systems and/or individuals are depicted as lines which connect these entities. Relations are of two types, Communication or Control. Communication is depicted with a thin line whereas the Control with a thick one. A Relation can be unidirectional or bidirectional, thus denoting the flow of information or influence or even material between the two entities. There is also a qualitative characterization of the relation but this is beyond the scope of this study.

DCSYM is accompanied by DCSYM CASE TOOL (2017). This is a software tool that has been being developed by Panagiotis Papaioannou and is used to design systems such as those presented in this paper. A simple example of a system using DCSYM notation is illustrated in Figure 2.

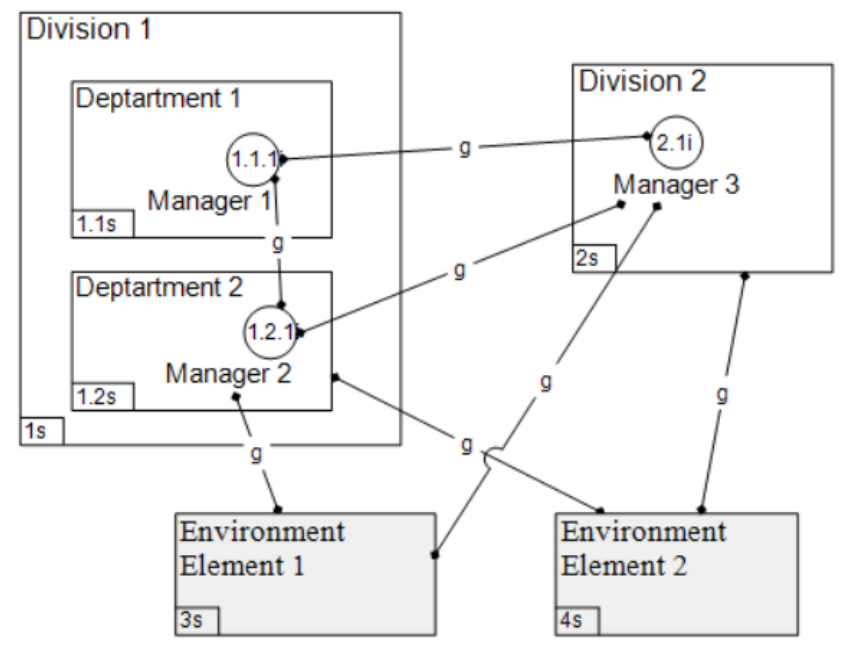

Figure 2. System example using DCSYM notation

Figure 3 illustrates the DCSYM model of a process based organization which is in interaction with the environment. 


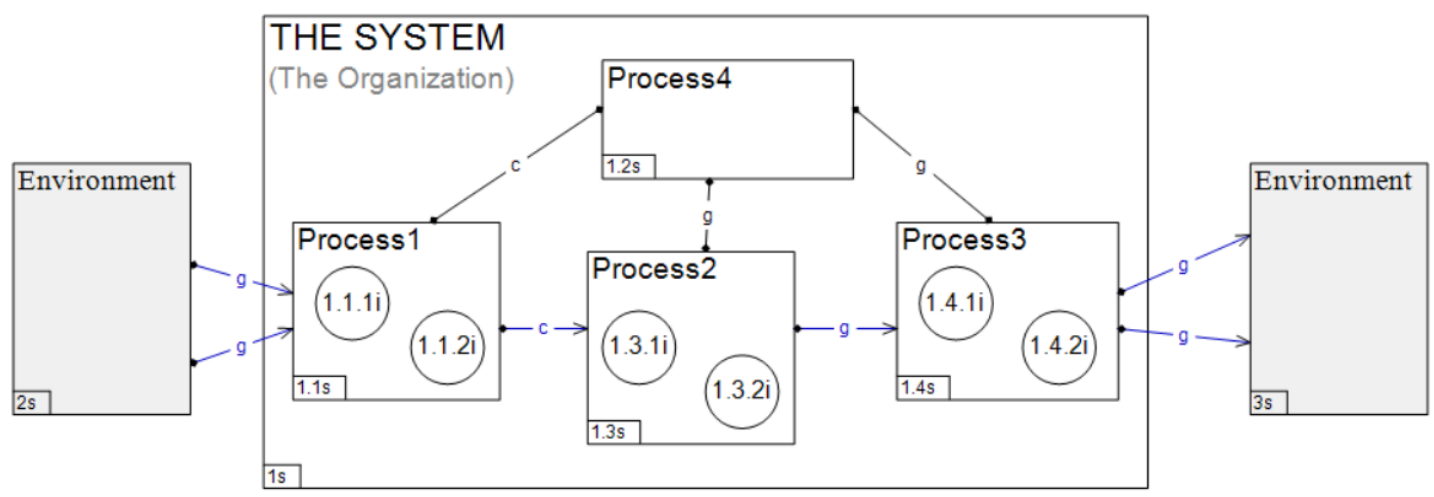

Figure 3. A system of processes modeled using DCSYM notation

\section{WORKING ON RELATIONS}

\section{Examining relations to identify risks}

Espejo and Reyes (2011) make a distinction between relations and relationships. They define relations as the interactions between individuals while relationships refer to established organizational interactions between organizational units or roles. In our study we use the term "relation" to refer to any interaction between any components of the model that describes the management system of the organization.

In order to develop our approach we consider an organization, or a part of it, which is organized as an ISO management system like ISO 9001:2015. This system is process-based; therefore its core consists of the processes and the interactions between them. This core system receives inputs from the environment whose description is a part of the context of the organization. The environment consists of materials or information strictly necessary for the process execution as well as legal requirements, stakeholders' expectations, organizational values and other intangible entities which can also be considered as inputs to the system. Of course, these system inputs are related and directed to specific processes within the system. The processes, the resources, the stakeholders' expectations including customers' requirements as well the legal and institutional framework and the organizational values, all these constitute an extended system which we shall examine in order to identify possible risk or opportunities events.

An example of such an extended system is presented in Figure 4 using the DCSYM modeling approach. In this model the system's main input, which is the customer's requirements, comes from the environment and is directed to Process1. The system's output, which is the final product, is delivered to the environment, most probably to the customer who requested the product produced. Other external influences or obligations like stakeholders' expectations or legal requirements are also inputs of this system and, through an internal way, they are applied as inputs to specific processes. Organizational values are also considered as part of the environment of the production system, thus being part of the extended system. 


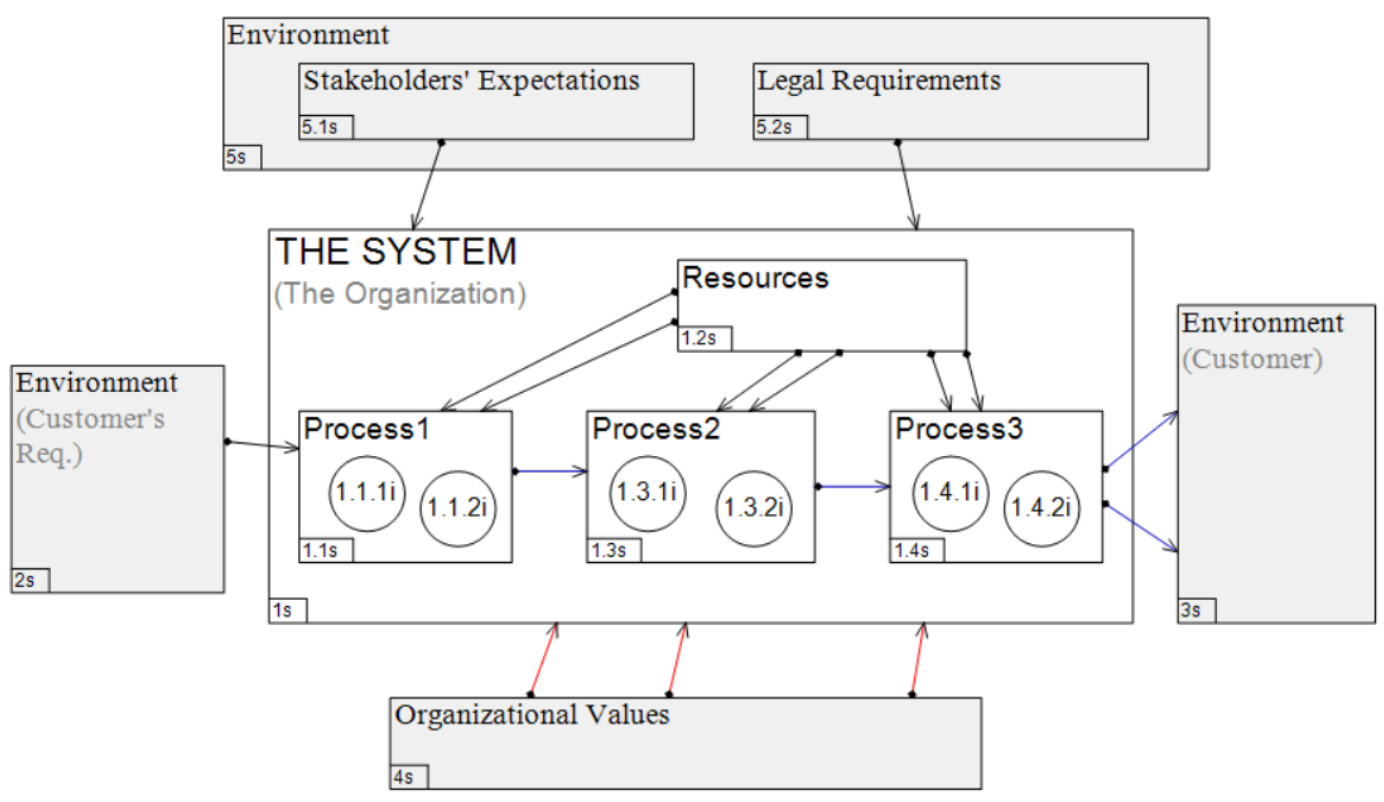

Figure 4. Model of the extended system

Given that, the behaviour of the system arises as a result of interactions between its components, we focus on the relations between system's elements. As explained previously, these relations represent inputs to the process that carry out the purpose of the system which, in final, is what the organization has to produce. Any variation or change related to a process input can affect the output of the process and, consequently, the dependent processes and the whole organization. According to this consideration, risk factors can be the absence, the quality, the appropriateness or the uncertainty of a process input. In our systemic model, each relation encompasses, or can be analysed into, one or more process inputs, therefore, relations can be considered as the source of possible risk events.

We continue by analysing the relations between system elements. Each process is considered as a subsystem of the main production system. Apart from the conventional process inputs, this subsystem receives also inputs from the environment like stakeholders' expectations, legal requirements and organizational values. Each of these relations is a point where a risk or opportunity event may occur and this is marked with a filled circle over the relation as shown in Figure 5.

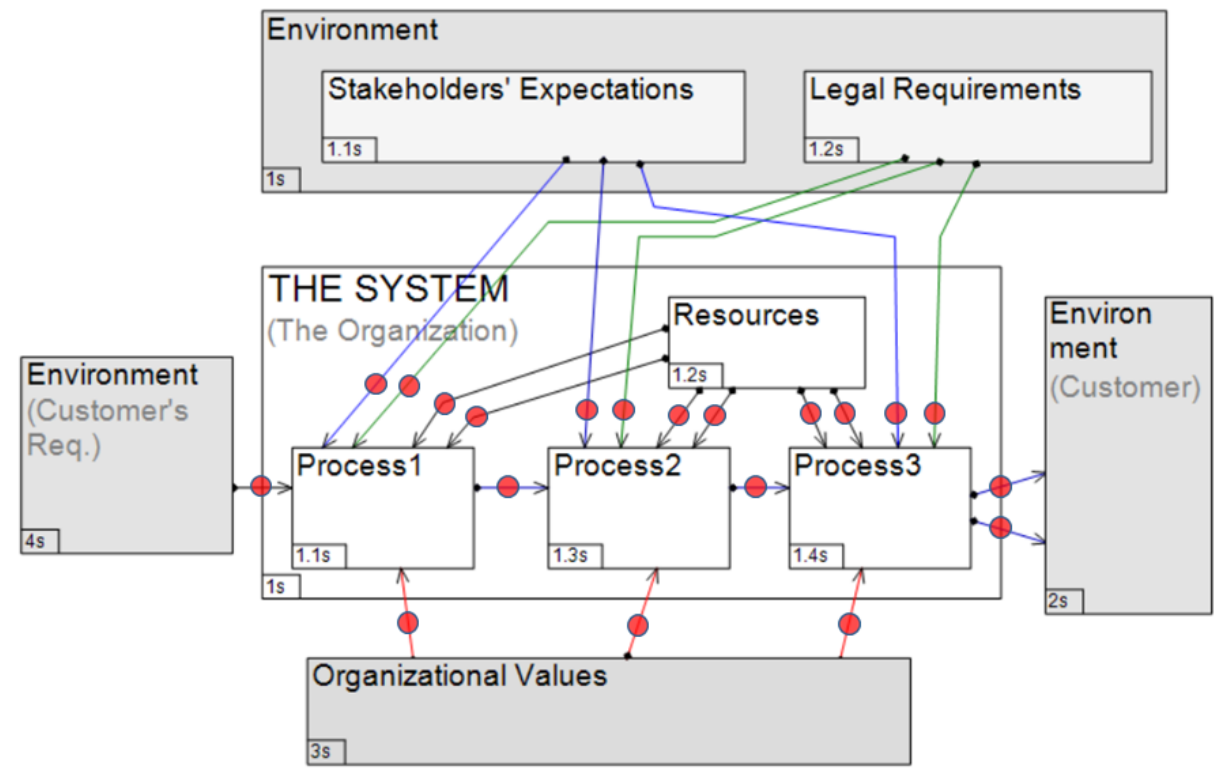

Figure 5. Model of the extended including points of a risk source 
As an example of identifying Risk Events we focus on Process1. This example has been kept generic in order to be easily associated with more than one of real world situations. Process1 receives inputs from the Customer as operational data but it has to take into account legal issues related to the specific business, the expectations of different stakeholders groups as well as norms and internal values established in the organization. This process is most likely to use general or specific resources to produce its output. All these can be considered as inputs to this process whose output is directed to a next process which is Process 2 in our example.

Examining each relation of the subsystem representing Process1, we can identify a list of possible Risk Events as shown in Table 1:

Table 1. Possible risk events for the Process 1 in Figure 5

\begin{tabular}{|c|c|}
\hline Relation & Risk Events examples \\
\hline Customer $\rightarrow$ Process 1 & $\begin{array}{l}\text { - } \text { Customer's order was lost } \\
\text { - Ambiguity in order's data } \\
\text { - } \quad \text { Requirements that cannot be met }\end{array}$ \\
\hline Stakeholders' Expect. $\rightarrow$ Process 1 & $\begin{array}{l}\text { - Unknown social groups' interests } \\
\text { - New social groups' interests }\end{array}$ \\
\hline Legal Requirements $\rightarrow$ Process 1 & $\begin{array}{l}\text { - Changes in laws concerning the product } \\
\text { - Changes in labor laws }\end{array}$ \\
\hline Organizational Values $\rightarrow$ Process 1 & $\begin{array}{l}\text { - } \\
\text { - New or change in corporate quality policy } \\
\text { - Need to comply in Hith a new standard }\end{array}$ \\
\hline Process $1 \rightarrow$ Process 2 & $\begin{array}{l}\text { Failure of Process } 1 \text { to produce its output and to } \\
\text { deliver it to Process } 2 \text {. }\end{array}$ \\
\hline
\end{tabular}

Likewise, other processes of our system can be identified.

A model, as the one in Figure 5, can additionally be represented as a mathematical Graph (a network of connected nodes), where each element is a node and the relations between the elements are the edges of the finite Graph. The application of Graph Theory has proven to be very effective in the design, analysis, management, and integration of complex systems (Peterson, 2015). Such a graph is also represented by the adjacency matrix which is a square matrix whose elements indicate whether the system components, one by one, are related or not. If the graph depicts the extended system, then the adjacency matrix shows the relations between the system components. Figure 6 illustrates an example of a network of processes represented as a graph and the corresponding adjacency matrix. In the adjacency matrix the intersection of a row and column indicates whether or not there is a relation from a process (a node) to another as well as the direction of that relation. 

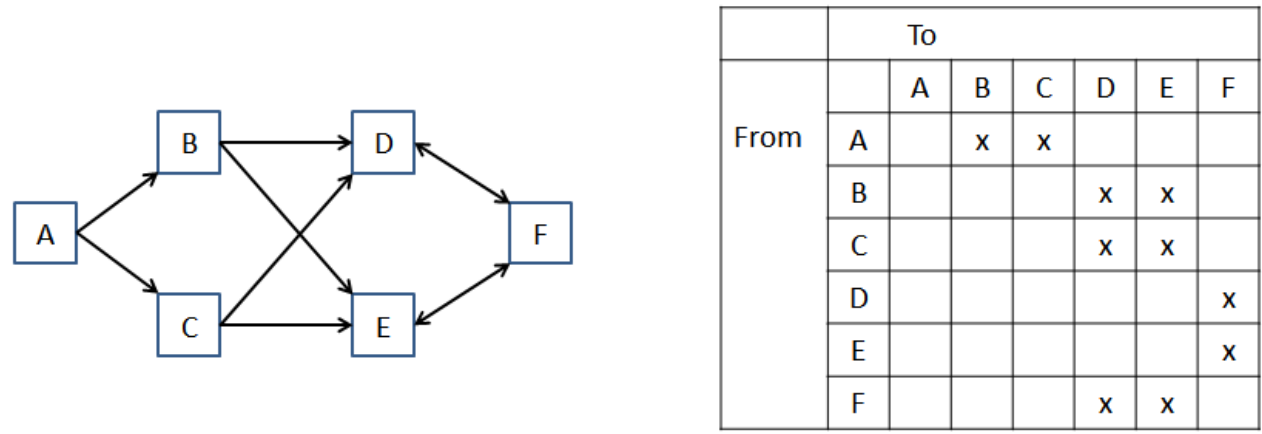

Figure 6: A network of processes as a graph and the corresponding adjacency matrix

Every relation, as explained before, is the source point of one or more possible risk events, therefore the set of risk events can be represented by a square matrix each element of which is a vector representing the risk events. In the following mathematical expression the array "A" represents the set of relations, each element "a" represents a relation and " $k$ " represents a risk event.

$$
\begin{aligned}
& \mathrm{A}=\left(\begin{array}{cccc}
a_{11} & a_{12} & \ldots & a_{1 n} \\
a_{21} & a_{22} & \ldots & a_{2 n} \\
\vdots & \vdots & \ddots & \vdots \\
a_{n 1} & a_{n 2} & \ldots & a_{n n}
\end{array}\right) \quad m, n \in \mathbb{Z} \\
& \text { where } \quad a_{i j}=\left(\begin{array}{llll}
k_{1} & \ldots & k_{i j}
\end{array}\right) \quad i, j \in \mathbb{Z}
\end{aligned}
$$

This is another, more systematic way, to identify possible risk events in the whole system.

\section{Examining relations to assess IT resources alignment}

Information systems and software in particular are characterized by a lot of emergent attributes and behaviors (Sommerville 2015; Ammann \& Offutt, 2016). For example, safety and security are classic emergent properties in system design. Dependability, efficiency or even acceptability are also properties exhibited at system level, hence forming emergent behaviors. Software emergent properties are attributed to subsystems interaction through interfaces (Pomorova \& Hovorushchenko, 2015).

The model mentioned previously can be used to assess how IT resources are aligned with the production system they serve. This is another perspective to the timeless issue of Business - IT alignment. Relations carry information and, in most cases within the organization, the interaction takes place through information systems. Thus, examining the relations between the components of a management system following an ISO standard such as ISO 9001:2015, can be the starting point for assessing the effectiveness of the organization's information systems and how well it integrates into the organization. The systemic and cybernetic point of view can be used to set the criteria for the above assessment.

The interaction between two management system components can be considered as the homeostatic loop between them as proposed by Stanford Beer (Beer, 1985) and modified by Espejo and Rays (2011). This interaction diffuses the variety through the organization or an institutional system in general. The one part of the relation tends to increase information or other variety, while the other part tries to absorb it and this occurs in both directions. Stanford Beer, introducing the First Principle of Organization, states that "varieties diffusing through an institutional system tend to equate. They should be designed to do so with minimum damage to people and to cost" (Beer, 1979). Thus one of the criteria should be how effectively the information systems serve the specific interaction between system components or processes in the sense of balancing the variety of the information exchanged.

Based on Beer's viable system model (VSM), five pathologies related to information channels and information systems within the organization are defined (Rios, 2010). These are: 1) Lack of 
information systems, 2) Fragmentation of information systems, 3) Lack of key communication channels, 4) Lack of or insufficient algedonic channels and 5) Communication channels incomplete or with inadequate capacity.

From the ISO standards point of view we can consider information as one of the resources of a process. The existence or appropriateness, or the uncertainty of the information flow between processes (or subsystems) is also an assessment of how the organization's information systems support the interaction between two specific processes.

In summary, examining the information transformation which takes place on each relation in our extended organizational model provides a means to assess information systems from a systemic point of view. This assessment is in this respect towards the integration of information systems into the process-based management system as well as the viability of the organization.

\section{Practical considerations - Implementation}

The proposed methodology assumes a thorough examination of all interactions between all elements of the larger system. The approach as illustrated in Figure 5 may be helpful in understanding the methodology in a small system but it becomes impractical as the system grows. In this case, the problem evolves to a data management issue and a more structured system for data processing is required.

To apply the proposed methodology, the prototype of a data processing system has been created consisting of a simple database and a minimal, yet functional user interface. The main entities in database are the components of the extended system described earlier, the links between them and the risk events associated with the links. Extra information as an attribute of each link holds the assessment of the information transformation between the two components. The entity representing a component may be a system processes or any of the other context elements. In fact, things are a bit more complex because each component is considered as a (sub) system which has specific interfaces (inputs and outputs) and these interfaces are the hook points of the links between system components.

The methodology has been applied in a small organization which provides educational services and operates an ISO 9001:2015 management system. The initial risk assessment was done employing the classical brainstorming approach. After that, the proposed methodology was applied. The first step was to create a model of the system including the environment elements according to the written documentation regarding the context of the organization. All risk events that had been identified were mapped onto the relations between the components and a preliminary assessment of the information transformation through each relation was performed.

\section{CONCLUSION}

In this study we attempted to model the organization as a system and to draw practical conclusions focusing on the relationships between system elements. We started by assuming that organizations are characterized by less or more complexity and systems thinking provides the means to deal with that. Our reasoning was based on the fact that the emergent behaviors of a system are due to its structure and more specifically to the relationships between the subsystems. The application field was the ISO management system standards family that follows the Annex SL normative, such as ISO 9001:2015, and the issues we dealt with were a) the risk identification and b) how IT systems are aligned with the management system. Finally, a pilot application of the methodology was applied to a small organization which operates a quality management system certified against ISO 9001: 2015 standard.

The results of the pilot application are considered satisfactory although it applied in retrospect in a previously designed system. Risks identified by employing a brainstorming process, were ex post mapped on the relations between system components. Given that Annex SL and ISO 9001:2015 requires that risks should be associated with the context and the processes, the proposed methodology provides a structured approach to accomplish this requirement.

Regarding the assessment of the IT systems, it was conducted on a systemic and cybernetic basis, but it helped to highlight existing problems and/or shortcomings and to propose future improvements. 
The proposed approach is domain-independent and it is planned to be applied to a small manufacturing industry which also operates an ISO 9001 quality management system for the same objective; to identify risks and to assess the information system.

The same approach can be used to examine or assess other system behaviors that can be considered as emergent. System reliability or organizational knowledge may be some of them.

\section{RÉFÉRENCES}

Ammann, P., \& Offutt, J. (2016). Introduction to software testing. Cambridge University Press.

Assimakopoulos, N., \& Theocharopoulos, I. (2009). "The Design and Control Systemic Methodology (DCSYM): a multi-agent modeling and operation platform". International Journal of Applied Systemic Studies, 2(3):193-217.

Aven, T., \& Renn, O. (2010). Risk Management and Governance. Springer, Berlin Heidelberg.

Beer, S. (1979). The Heart of Enterprise. John Wiley, Chichester

Beer, S. (1985) Diagnosing the system for organizations. John Wiley, Chichester

Bertalanffy, L. von (1968). General System Theory: Foundations, Development, Applications. George Braziller, Inc., New York, NY, USA.

Checkland, P. (1999). Systems Thinking, Systems Practice. John Wiley \& Sons, New York, NY, USA:

Conant, R. C. \& Ashby, W. R. (1970). "Every good regulator of a system must be a model of that system". International Journal of Systems Science, 1(2):89-97

DCSYM CASE TOOL (2017). Retrieved: Sept. 20, 2017 from https://sites.google.com /site/systemsandcomplexity/dcsym-case-tool.

Espejo, R., \& Reyes, A. (2011). Organizational systems: Managing complexity with the viable system model. Springer Science \& Business Media.

Fabac, R. (2010). "Complexity in organizations and environment-adaptive changes and adaptive decision-making”. Interdisciplinary Description of Complex Systems, 8(1):34-38.

Flood, R. L. \& Carson, E. R. (1993). Dealing with Complexity: An Introduction to the Theory and Application of Systems Science, Second Edition. Plenum Press, New York.

Fromm, J., (2005). "Types and forms of emergence". Retrieved: Sept 20, 2017 from https://arxiv.org/ftp/nlin/papers/0506/0506028.pdf

Ganco, M. (2014). Complexity Theory. Wiley Encyclopedia of Management.

Gharajedaghi, J. (2011). Systems thinking: Managing chaos and complexity: A platform for designing business architecture. Elsevier.

Hitchins, D. K. (2007). Systems engineering: a 21 st century systems methodology. John Wiley \& Sons. Honderich. T. (1995). The Oxford Companion to Philosophy. Oxford University Press, New York

INCOSE (2014). A World in Motion: Systems Engineering Vision. Retrieved: Sept. 20, 2017 from $\mathrm{http} / / / \mathrm{www}$.incose.org/docs/default-source/aboutse/se-vision-2025.pdf

ISO (2009). "ISO 31010: 2009 - Risk Management - Risk Assessment Techniques". International Organization for Standardization, Geneva.

ISO (2015a). "Quality management principles 2015". International Organization for Standardization, retrieved: Sept. 20, 2017 from www.iso.org/publication/PUB100080.html

ISO (2015b). "ISO 9001:2015 Quality Management Systems - Requirements". International Organization for Standardization, Geneva.

ISO (2015c). "Risk-Based Thinking in ISO 9001:2015". International Organization for Standardization, retrieved: Sept. 20, 2017 from www.iso.org/tc176/sc02/public.

ISO (2016). "Annex SL (normative), Proposals for management system standards". ISO/IEC Directives, Part 1, Consolidated ISO Supplement, Procedures specific to ISO, Seventh edition (2016). 
ISO (2017). "Management system standards". International Organization for Standardization, retrieved: Sept. 20, 2017 from www.iso.org/management-system-standards.html

Johansen, I. L., \& Rausand, M. (2014). "Defining complexity for risk assessment of sociotechnical systems: A conceptual framework". Proceedings of the Institution of Mechanical Engineers, Part O: Journal of Risk and Reliability, 228(3), 272-290.

Johnson, N. (2009). Simply complexity: A clear guide to complexity theory. One-World Publications, Oxford.

Langefors, B., (1995). Essays in Infology: Summing Up and Planning for the Future, Studentlitteratur, Lund.

Loper, M. L \& Register, A. (2015), "Introduction to Modeling and Simulation". Modeling and Simulation in the Systems Engineering Life Cycle Core Concepts and Accompanying Lectures, Chapter 1, (Margaret L. Loper, ed), Springer-Verlag, London

Peterson, T. A. (2015). "Dynamic Visualization of Complex Systems". NDIA 18th Annual Systems Engineering Conference, October 26-29, 2015.

Pomorova, O., \& Hovorushchenko, T. (2015). "The way to detection of software emergent properties". Intelligent Data Acquisition and Advanced Computing Systems: Technology and Applications (IDAACS), 2015 IEEE 8th International Conference, Vol.2:779-784.

Ríos, P. J. (2010). "Models of organizational cybernetics for diagnosis and design". Kybernetes 39(9/10):1529-1550.

Ryan, A. (2007). A Multidisciplinary Approach to Complex Systems Design. PhD thesis, The University of Adelaide.

Sargut, G., \& McGrath, R. G. (2011). "Learning to live with complexity". Harvard business review, 89(9):68-76.

Schneider, A., Wickert, C., \& Marti, E. (2016). "Reducing complexity by creating complexity: a systems theory perspective on how organizations respond to their environments". Journal of Management Studies, 54(2):182-208.

Senge, P. M. (2006). The fifth discipline: The art and practice of the learning organization. Doubleday Currency, New York, NY, USA.

Sillitto, H. G. (2010). "Design principles for Ultra- Large- Scale (ULS) Systems". INCOSE International Symposium, 20(1):63-82.

Sommerville I., (2015). Software Engineering, 10th ed., Pearson Education Limited

Wade, J., \& Heydari, B. (2014). "Complexity: Definition and Reduction Techniques". Proceedings of the Poster Workshop at the 2014 Complex Systems Design \& Management International Conference (213-226).

Zimmermann, R. E. (2017). "Matter and information as attributes of substance". The European Physical Journal Special Topics, 226(2):177-180. 